Article

\title{
Antioxidant Activity and Sensory Improvement of Angelica dahurica cv. Yubaizhi Essential Oil on Sunflower Oil during High-temperature Storage
}

\author{
Dongying Wang ${ }^{1, *(\mathbb{D}}$, Yudong Meng ${ }^{1}$, Chenxin Wang ${ }^{2, *}$, Xuede Wang ${ }^{1}$ and Francesca Blasi ${ }^{3}(\mathbb{D}$ \\ 1 College of Food Science and Technology, Henan University of Technology, Zhengzhou 450001, China; \\ mengyudong96@sina.com (Y.M.); 13903865594@126.com (X.W.) \\ 2 Center for Life Sciences, Peking University, Beijing 100871, China \\ 3 Department of Pharmaceutical Sciences, University of Perugia, Via San Costanzo, 06126 Perugia, Italy; \\ francesca.blasi@unipg.it \\ * Correspondence: dywang@haut.edu.cn (D.W.); wangchx@pku.edu.cn (C.W.); \\ Tel.: +86-371-67758022 (D.W.); +86-10-62766692 (C.W.)
}

Received: 16 March 2020; Accepted: 24 March 2020; Published: 30 March 2020

\begin{abstract}
The oxidative state of sunflower oil during high-temperature storage has been facing large challenges. In the study, the antioxidant effect of the essential oil of Angelica dahurica cv. Yubaizhi (ADEO) in sunflower oil was explored. In the high-temperature storage for 24 days at $65^{\circ} \mathrm{C}, \mathrm{ADEO}$ (800 ppm) was able to markedly inhibit the development of the acid value (AV), peroxide value $(\mathrm{PV}), p$-anisidine value $(\mathrm{AnV})$, total oxidation value (TOTOX), thiobarbituric acid reactive substances (TBARS), total polar compounds (TPC), and the absorbance at 232 and $268 \mathrm{~nm}(p<0.01$ or $p<0.05)$ of sunflower oil and to prominently inhibit the transformation between unsaturated fatty acids (UFA) and saturated fatty acids (SFA). Interestingly, the synergistic effect of ADEO (400 ppm) and tert-butyl hydroquinone (TBHQ, $100 \mathrm{ppm}$ ) was demonstrated. Furthermore, the sensory attributes such as flavor, taste, and overall acceptability of oxidized sunflower oil added by ADEO at 200, 400, and $800 \mathrm{ppm}$ were memorably elevated $(p<0.05)$. Besides, one of its main compounds, myrcene, was demonstrated to be its active compound during the whole investigation. Consequently, TBHQ at $200 \mathrm{ppm}$ could be substituted by ADEO at $800 \mathrm{ppm}$ and myrcene at $69.8 \mathrm{ppm}$ in the high-temperature storage at $65^{\circ} \mathrm{C}$ of sunflower oil.
\end{abstract}

Keywords: antioxidant activity; sensory improvement; Angelica dahurica cv. Yubaizhi; sunflower oil

\section{Introduction}

During the high-temperature storage of oils and fats and of foods comprising fat, oxidative rancidity is still an important reason of their quality reduction, although plenty of synthetic antioxidants have long been frequently applied, including butylated hydroxyanisole (BHA), butylated hydroxytoluene (BHT), and tert-butyl hydroquinone (TBHQ) [1]. After all, the wide use of these synthetic antioxidants has triggered a series of serious problems concerning their edible safety in view of their metabolism, absorption, and accumulation in several organs and tissues of human body [2]. For the most powerful synthetic antioxidant, TBHQ, several western countries like the USA have assessed its chemical toxicology and have established an upper limit of $200 \mathrm{ppm}$ for its additive amount in foods. Furthermore, BHT and BHA have been restricted in many countries as well [3]. In consequence, to search for effective natural antioxidants is highly necessary, after all, natural antioxidants have the following advantages compared with synthetic antioxidants [4]:

(i) These natural antioxidants are often extracted from plants used for herbs and spices that have been consumed by people for quite a long history, which are not the case for synthetic antioxidants. 
(ii) The consumers' acceptance of natural antioxidants is much higher because they are considered much safer.

Nowadays, plenty of reports have published about the extracts/compounds from herbs and spices displaying antioxidant effects, and some of them could be used in the accelerated storage or deep frying of edible oils instead of synthetic antioxidants [5-7]. For example, in the systematically comparative investigation of 26 culinary spices, the spices with high contents of phenolic constituents including clove, cinnamon, oregano, sage, thyme, and rosemary were demonstrated to be potent excellent antioxidants [8]. In the detailed comparative exploration of the $\mathrm{H}_{2} \mathrm{O}$ and/or EtOH extracts from 9 culinary spices, the plants with high contents of phenolic compounds including Illicium verum, Laurus nobilis, Foeniculum vulgare, Pericarpium zanthoxyli, and Cinnamomum aromaticum also had high antioxidant activities, indicating that these spices might be potentially used as natural antioxidants in food [9]. What needs to be emphasized is that, among the natural antioxidants from spices/herbs, the essential oils have drawn more and more attentions from researchers all over the world [10]. For instance, the essential oils of Zataria multiflora and Carum copticum could prevent sunflower oil from oxidation during accelerated storage and the synthetic antioxidants like BHA and BHT could be substituted with higher concentrations of essential oils [11].

Angelica dahurica cv. Yubaizhi, as one local cultivar of A. dahurica in Yuzhou, China, has long been used as Chinese medicine in the treatment of headaches, toothaches, nose congestion caused by cold/fever, swelling, and pain caused by sores/wounds and been used as the primary ingredient of plenty of famous Chinese medicine formulas including Yuanhu Zhitong tablets [12]. In the continuing phytochemical investigation and pharmacological exploration of the plant, many secondary metabolites including essential oils, polysaccharides, alkaloids, and coumarins have been isolated, and most of them exhibited interesting biological effects such as antioxidant effect and anti-inflammatory effect [12,13]. Furthermore, the plant has been used as a spice as well [13]. Among them, the essential oil of the plant was demonstrated to have antioxidant effect in preliminary studies $[13,14]$. However, to the best of our knowledge, there are no articles on the prevention of oxidation of edible oils using the essential oil of the plant until now.

Therefore, the purpose herein is to investigate the antioxidant effect for Angelica dahurica cv. Yubaizhi essential oil (ADEO) in the high-temperature storage of sunflower oil, which is the fourth largest source of vegetable oil after the oils from soybean, rapeseed, and cottonseed [15].

\section{Materials and Methods}

\subsection{Materials and Reagents}

The root parts of A. dahurica cv. Yubaizhi harvested in the countryside area of Yuzhou, Henan of China was purchased from the Supermarket of Chinese Medicine in Yuzhou, Henan of China. Sunflower oil manufactured by Dongsheng, Shangqiu, China using Helianthus annuus obtained from Kuitun, China was purchased from the Shop of Dennis Supermarket at Hongzhuan Street, Zhengzhou, China. Additionally, all the other reagents were provided by Senbo Biotechnology Co., Ltd., Zhengzhou, China.

\subsection{Extraction of $A D E O$}

The extraction of ADEO was carried out based on Wang et al.'s method [16]. The root parts of A. dahurica cv. Yubaizhi were crushed into uniform powder of particles with diameter less than $1 \mathrm{~mm}$ by means of a multifunctional grinder for $10 \mathrm{~min}$ at 25,000 r/min (400Y, Boou, China), and then, the powder was divided into 10 parts at random (1000 g each). Each part of the powder was placed in a flask $(3000 \mathrm{~mL})$ with water $(1000 \mathrm{~mL})$ and hydrodistilled by means of a steam distillation apparatus (XH-1000, Xinhu, China) at $120 \mathrm{v}^{\circ} \mathrm{C}$ for $4 \mathrm{~h}$. After the collection of the distillate, $250 \mathrm{~mL}$ of ethyl acetate was used to obtain the organic phase by partition. The whole organic phase of the powder was put together to obtain ADEO, which was subsequently dried over anhydrous $\mathrm{Na}_{2} \mathrm{SO}_{4}$ and preserved at $-4{ }^{\circ} \mathrm{C}$ in a deep-brown 
flask in the freezer until they were analyzed by gas-chromatography/mass-spectrometry (GC-MS) and gas-chromatography/flame-ionization-detector (GC-FID) and involved in high-temperature storage.

\subsection{GC-MS and GC-FID of ADEO}

The GC-MS and GC-FID of ADEO were carried out based on Tabanca et al.'s method [17]. Briefly, operating at $70 \mathrm{eV}$ ionization energy, GC-MS was done using an Agilent 5975 system equipped with an Innowax column $(60 \mathrm{~m} \times 0.25$ inner diameter, $0.25 \mu \mathrm{m}$ film thickness Agilent, Palo Alto, USA). The split ratio was set as 1:50, and the carrier gas $\mathrm{He}$ was at $0.8 \mathrm{~mL} / \mathrm{min}$. Above all, the oven temperature was programmed as being kept for $10 \mathrm{~min}$ at $60^{\circ} \mathrm{C}$, subsequently ascending at $4{ }^{\circ} \mathrm{C} / \mathrm{min}$ to $220^{\circ} \mathrm{C}$, being kept for $10 \mathrm{~min}$, and ascending at $1^{\circ} \mathrm{C} / \mathrm{min}$ to $240{ }^{\circ} \mathrm{C}$. The injector temperature was $250{ }^{\circ} \mathrm{C}$, and mass range was 35-450. The chemical constituents of ADEO were identified via searching NIST Chemistry WebBook (https://webbook.nist.gov). For GC-FID analysis, it was done on an Agilent $6890 \mathrm{~N}$ system installed with the Innowax column, and the temperature of FID detector was $300{ }^{\circ} \mathrm{C}$. The relative percentage in the total peak area in the chromatograph of every separated compound was acquired via integrating the corresponding peak in the GC-FID spectrum.

\subsection{Preparation of Sunflower Oil Flavored by ADEO}

In the preparation for sunflower oil flavored by ADEO, sunflower oil was added ADEO directly. For sunflower oil samples I, II, and III, the ADEO was added at concentrations of 200, 400, and 800 ppm, respectively. For sample IV, TBHQ, used as positive control, was added at the concentration of its legal limit of China (200 ppm). Furthermore, to explore the synergistic effect of ADEO and TBHQ, sample V was added ADEO at a concentration of 400 ppm and TBHQ at a concentration at $100 \mathrm{ppm}$. For sample VI, nothing was added to make it as a blank control sample. When the preparation completed, these sunflower oil samples (each $4.0 \mathrm{~kg}$ ) were immediately stored in triplicates at $65^{\circ} \mathrm{C}$ at an oven. In accordance with Sadeghi et al.'s study, $24 \mathrm{~h}$ of storage in the high-temperature at $65^{\circ} \mathrm{C}$ is equal to 1 month of storage in the normal-temperature [18]. Every 6 days, the chemical analysis of sunflower oils was carried out in 24 successive days. Every 12 days, the chemical composition of the sunflower oil samples was analyzed.

\subsection{Measurement of $A V, P V, A n V$, and TOTOX Values}

The measurement for acid value (AV), peroxide value (PV) and $p$-anisidine value (AnV) were performed in accordance with National Standard of China 5009.229-2016, 5532-2008, 5009.227-2016, and 24304-2009, respectively. The total oxidation value (TOTOX) was figured out by the following equation: $\mathrm{TOTOX}=2 \mathrm{PV}+\mathrm{AnV}[19]$.

\subsection{Measurement of TBARS and TPC Values}

Thiobarbituric acid reactive substances (TBARS) was measured according to National Standard of China (5009.181-2016) with a little modification. In brief, together with $50 \mathrm{~mL}$ of mixed solution (trichloroacetic acid (TCA, 7.5\%)-ethylene diamine tetraacetic acid (EDTA, 0.1\%)), $5.0 \mathrm{~g}$ of sunflower oil was put into a $100-\mathrm{mL}$ flask, shaken for $30 \mathrm{~min}$ at $50{ }^{\circ} \mathrm{C}$, cooled to normal-temperature, and filtered by two-layer paper with the bore diameter of $1-3 \mu \mathrm{m}$ to get the subsequent filtrate. Meanwhile, the standard solutions for malondialdehyde (MDA) of $0.01,0.05,0.10,0.15$, and $0.25 \mu \mathrm{g} / \mathrm{mL}$ were prepared by malondialdehyde acetaldehyde using a series of dilution processes. For determination, $5 \mathrm{~mL}$ of subsequent filtrate/standard solution and $5 \mathrm{~mL}$ of thiobarbituric acid (TBA) solution $(0.02 \mathrm{~mol} / \mathrm{L})$ were added into a $25 \mathrm{~mL}$ colorimetric tube, and then, the tube was heated and cooled to normal temperature. The absorbance at $532 \mathrm{~nm}$ of subsequent filtrate/standard solution was determined, while the TBARS of the sunflower oil samples was figured out by a standard curve drawn using standard solutions.

Total polar compounds (TPC) was measured according to National Standard of China (5009.202-2016) with a little modification. In brief, $25.0 \mathrm{~g}$ of silica gel 60 was put into a column 
(500 $\mathrm{mm}$ length and $25 \mathrm{~mm}$ inner diameter). After $2.50 \mathrm{~g}$ of sunflower oil was subjected to the column, it was eluted by $200 \mathrm{~mL}$ of the solvent system of petroleum ether and ether $(87: 13, \mathrm{v} / \mathrm{v})$ to get rid of nonpolar components. The weight of nonpolar components was acquired after the solvent system was dried by oven under $40{ }^{\circ} \mathrm{C}$ and $0.1 \mathrm{MPa}$ for $30 \mathrm{~min}$. TPC was figured out using the following equation: TPC $(\%)=\left(\mathrm{W}-\mathrm{W}_{1}\right) / \mathrm{W} \times 100$, where $\mathrm{W}$ was sunflower oil weight and $\mathrm{W}_{1}$ was the nonpolar component weight.

\subsection{Determination of $K_{232}$ and $K_{268}$ Values}

The determination of $\mathrm{K}_{232}$ and $\mathrm{K}_{268}$ values of sunflower oil was carried out in terms of National Standard of China (22500-2008) with a little modification. Briefly, a $10 \mathrm{~mL}$ volumetric flask full of isooctane was added $0.1 \mathrm{~g}$ of sunflower oil. At 232 and $268 \mathrm{~nm}$, the absorbance of the sunflower oil samples was determined (UV-2550, Shimadzu, Japan).

\subsection{Chemical Analysis of Fatty Acid Composition}

The chemical analysis for the fatty acid composition were carried out according to Wang et al.'s method [16].

\subsection{Sensory Evaluation of Oxidized Sunflower Oil Samples Treated with AEDO}

As reported by Chandran et al., after 24 days of storage, the sensory evaluation for the ADEO-flavored sunflower oil samples was performed using 100 consumer representatives of sunflower oil in Xinyuan Wholesale Food Market of Guangzhou, Guangzhou, China [20]. Before the sensory evaluation, all panelists were demanded to intensively read over the illustrations on the sensory blank, the meanings of the sensory attributes were minutely illustrated to them to reduce their misunderstandings, and sunflower oil samples were coded using 3-digit numbers and presented in a randomized arrangement. A 5-point hedonic scale was applied to assess the sensory attributes of flavor, taste, and overall acceptability of the sunflower oil samples (extremely dislike- 1 , moderately dislike - 2, neither dislike nor like-3, moderately like-4, and extremely like-5). The mean sensory scores were calculated.

\subsection{Influence of Active Compounds from ADEO on Sunflower Oil Samples}

First, the fractionation guided by antioxidant activity of ADEO was performed using the dot-blot test on thin-layer chromatography (TLC) by means of silica gel Al plates [21]. Briefly, ADEO (10 $\mu \mathrm{L})$ was spotted on TLC plate, and then, the plate was eluted using hexane-ethyl acetate $(75: 25, \mathrm{v} / \mathrm{v})$. After dried and sprayed with of methanol solution of 1,1-diphenyl-2-picrylhydrazyl (DPPH) (160 $\mu \mathrm{M})$, the luminous yellow spots on the purple surface of the plate was regarded as active compounds with scavenging effect on the DPPH free radicals. For the separation of the luminous yellow spots, the preparative TLC plates also made of silica gel Al were applied and eluted using hexane-ethyl acetate (75:25, v/v), and the luminous yellow spots with the same Rf values were eluted using ether. Three compounds including myrcene, terpinen-4-ol, and cryptone were obtained, and the chemical structures were confirmed using ${ }^{1} \mathrm{H}-\mathrm{NMR}$ and High Resolution Electrospray Ionization Mass Spectroscopy (HRESIMS) (published elsewhere).

Second step, in the assessment for their antioxidant activity in sunflower oil, myrcene (800 ppm $\times 8.72 \%=69.8 \mathrm{ppm})$, terpinen-4-ol $(800 \mathrm{ppm} \times 8.01 \%=64.1 \mathrm{ppm})$, and cryptone $(800 \mathrm{ppm} \times 6.67 \%$ $=53.4 \mathrm{ppm}$ ) were added into sunflower oil at the corresponding concentrations in ADEO to gain the sunflower oil samples (Table 1, $4.0 \mathrm{~kg}$ each) MY-69.8, TE-64.1, and CR-53.4, respectively, together with sunflower oil samples control (added nothing) and TBHQ (200 ppm, TBHQ-200). Subsequently, the high-temperature storage of sunflower oil samples for 24 days at $65{ }^{\circ} \mathrm{C}$ was carried out again. In the high-temperature storage process, the values of AV, PV, AnV, TOTOX, TBARS, TPC, $\mathrm{K}_{232}$, and $\mathrm{K}_{268}$ were measured every 6 days and the sensory evaluation of sunflower oil was performed. 


\subsection{Statistical Analysis}

Unless otherwise indicated, the experimental data were exhibited in mean $\pm \operatorname{SD}(n=10)$ in figures and tables and exhibited in means in text. The experimental data among the sunflower oil samples were analyzed via one-way analysis of variance (ANOVA) test, where the probability $p<0.05$ and $p<0.01$ were labeled as statistically significant and highly significant, respectively.

\section{Results and Discussion}

\subsection{Chemical Composition of ADEO}

As one famous spice/one important herb with special fragrance in China, the volatile oil of A. dahurica has been repeatedly extracted and its chemical composition has been frequently explored [22]. The previous reports described that both of extraction yields and chemical compositions were obviously different if the plant materials of the spice came from different regions in China. In Zhao et al.'s investigations, the extraction yield of the essential oil from $A$. dahurica cultivated in Anguo, China was $0.06 \%(\mathrm{~mL} / \mathrm{g})$, and 111 compounds including $\beta$-terpinene $(\mathrm{w} / \mathrm{w}, 3.53 \%), \beta$-elemene $(6.20 \%)$, and 3-carene $(12.70 \%)$ were identified from the plant materials. The extraction yield of A. dahurica cultivated in Tonghua, China was $0.28 \%(\mathrm{w} / \mathrm{w})$, and 76 compounds including $1 \mathrm{R}-\alpha$-pinene (3.85\%), 1-dodecanol (5.74\%), 3-carene (10.94\%), $\alpha$-limonene $(15.25 \%)$, and tetradecanol $(19.43 \%)$ were identified $[18,23]$. In this study, $144.2 \mathrm{~mL}$ of essential oil was extracted from $10 \mathrm{~kg}$ of root parts of A. dahurica cv. Yubaizhi, with an extraction yield of $1.4 \%(\mathrm{~mL} / \mathrm{g})$. Furthermore, as exhibited in Table 1, only 38 compounds have been identified. Among them, $\alpha$-pinene (44.91\%), myrcene (8.72\%), terpinen-4-ol (8.01\%), cryptone $(6.67 \%)$, 1-dodecanol $(6.43 \%)$, and sabinene $(3.42 \%)$ were regarded as main components of the essential oil. Compared with Tabanca et al.'s study, all the compounds identified here excepted undecane, tridecane, 2-nonanol, carvacrol methyl ether, and sesquisabinene have been identified, and the main components here were also considered as main components by Tabanca et al. [17]. Nevertheless, there were 43 compounds identified by them, although the relative percentages of some compounds were low. In addition, there were much difference between the results of the study and that of Zhao et al.' investigations, where the A. dahurica were harvested from Anguo, China and Tonghua, China, and 111 and 76 compounds were identified, with most of compounds obtained here not found in the two studies. Besides, the main compounds of the two studies were 3 -carene, $\beta$-elemene, $\beta$-terpinene, $\beta$-myrcene, $\gamma$-elemene, $\beta$-phellandrene and $\beta$-maaliene, tetradecanol, $\alpha$-limonene, 3-carene, 1 -dodecanol, and $1 \mathrm{R}-\alpha$-pinene, which confirmed that the place of origin of the plant materials was able to play a significant part in chemical compositions and extraction yields for the essential oils [18,23]. 
Table 1. Chemical composition (w/w, mean value \pm SD) of Angelica dahurica cv. Yubaizhi essential oil (ADEO).

\begin{tabular}{|c|c|c|c|c|}
\hline No. & $\mathrm{RRI}^{\mathrm{a}}$ & Compound Name ${ }^{b}$ & Formula & $w / w(\%)$ \\
\hline 1 & 1032 & $\alpha$-Pinene & $\mathrm{C}_{10} \mathrm{H}_{16}$ & $44.91 \pm 4.27$ \\
\hline 2 & 1035 & $\alpha$-Thujene & $\mathrm{C}_{10} \mathrm{H}_{16}$ & $0.29 \pm 0.04$ \\
\hline 3 & 1048 & 2-Methyl-3-buten-2-ol & $\mathrm{C}_{5} \mathrm{H}_{10} \mathrm{O}$ & $0.22 \pm 0.03$ \\
\hline 4 & 1076 & Camphene & $\mathrm{C}_{10} \mathrm{H}_{16}$ & $0.44 \pm 0.04$ \\
\hline 5 & 1100 & Undecane & $\mathrm{C}_{11} \mathrm{H}_{24}$ & $0.15 \pm 0.03$ \\
\hline 6 & 1118 & $\beta$-Pinene & $\mathrm{C}_{10} \mathrm{H}_{16}$ & $1.68 \pm 0.14$ \\
\hline 7 & 1132 & Sabinene & $\mathrm{C}_{10} \mathrm{H}_{16}$ & $3.42 \pm 0.32$ \\
\hline 8 & 1159 & $\delta$-3-Carene & $\mathrm{C}_{10} \mathrm{H}_{16}$ & $0.14 \pm 0.02$ \\
\hline 9 & 1174 & Myrcene & $\mathrm{C}_{10} \mathrm{H}_{16}$ & $8.72 \pm 0.81$ \\
\hline 10 & 1203 & Limonene & $\mathrm{C}_{10} \mathrm{H}_{16}$ & $1.88 \pm 0.16$ \\
\hline 11 & 1218 & $\beta$-Phellandrene & $\mathrm{C}_{10} \mathrm{H}_{16}$ & $0.52 \pm 0.04$ \\
\hline 12 & 1280 & p-Cymene & $\mathrm{C}_{10} \mathrm{H}_{14}$ & $2.11 \pm 0.18$ \\
\hline 13 & 1296 & Octanal & $\mathrm{C}_{8} \mathrm{H}_{16} \mathrm{O}$ & $0.12 \pm 0.03$ \\
\hline 14 & 1300 & Tridecane & $\mathrm{C}_{13} \mathrm{H}_{28}$ & $0.15 \pm 0.02$ \\
\hline 15 & 1479 & $\delta$-Elemene & $\mathrm{C}_{15} \mathrm{H}_{24}$ & $0.25 \pm 0.03$ \\
\hline 16 & 1521 & 2-Nonanol & $\mathrm{C}_{9} \mathrm{H}_{20} \mathrm{O}$ & $0.16 \pm 0.02$ \\
\hline 17 & 1586 & Pinocarvone & $\mathrm{C}_{10} \mathrm{H}_{14} \mathrm{O}$ & $0.64 \pm 0.07$ \\
\hline 18 & 1594 & trans- $\beta$-Bergamotene & $\mathrm{C}_{15} \mathrm{H}_{24}$ & $0.15 \pm 0.02$ \\
\hline 19 & 1600 & $\beta$-Elemene & $\mathrm{C}_{15} \mathrm{H}_{24}$ & $2.16 \pm 0.18$ \\
\hline 20 & 1611 & Terpinen-4-ol & $\mathrm{C}_{10} \mathrm{H}_{18} \mathrm{O}$ & $8.01 \pm 0.75$ \\
\hline 21 & 1614 & Carvacrol methyl ether & $\mathrm{C}_{11} \mathrm{H}_{16} \mathrm{O}$ & $1.41 \pm 0.16$ \\
\hline 22 & 1620 & Selina-5,11-diene & $\mathrm{C}_{15} \mathrm{H}_{24}$ & $0.18 \pm 0.02$ \\
\hline 23 & 1668 & (Z)- $\beta$-Farnesene & $\mathrm{C}_{15} \mathrm{H}_{24}$ & $0.14 \pm 0.02$ \\
\hline 24 & 1669 & Sesquisabinene & $\mathrm{C}_{15} \mathrm{H}_{24}$ & $0.14 \pm 0.02$ \\
\hline 25 & 1688 & Selina-4,11-diene & $\mathrm{C}_{16} \mathrm{H}_{28}$ & $0.86 \pm 0.09$ \\
\hline 26 & 1690 & Cryptone & $\mathrm{C}_{9} \mathrm{H}_{14} \mathrm{O}$ & $6.67 \pm 0.66$ \\
\hline 27 & 1741 & $\beta$-Bisabolene & $\mathrm{C}_{15} \mathrm{H}_{24}$ & $0.16 \pm 0.02$ \\
\hline 28 & 1742 & $\beta$-Selinene & $\mathrm{C}_{15} \mathrm{H}_{24}$ & $0.13 \pm 0.02$ \\
\hline 29 & 1744 & $\alpha$-Selinene & $\mathrm{C}_{15} \mathrm{H}_{24}$ & $0.15 \pm 0.01$ \\
\hline 30 & 1804 & Myrtenol & $\mathrm{C}_{10} \mathrm{H}_{16} \mathrm{O}$ & $0.08 \pm 0.01$ \\
\hline 31 & 1849 & Cuparene & $\mathrm{C}_{15} \mathrm{H}_{22}$ & $1.58 \pm 0.14$ \\
\hline 32 & 1854 & Germacrene-B & $\mathrm{C}_{15} \mathrm{H}_{24}$ & $0.23 \pm 0.03$ \\
\hline 33 & 1974 & 1-Dodecanol & $\mathrm{C}_{12} \mathrm{H}_{26} \mathrm{O}$ & $6.43 \pm 0.58$ \\
\hline 34 & 2008 & Caryophyllene oxide & $\mathrm{C}_{15} \mathrm{H}_{24} \mathrm{O}$ & $1.16 \pm 0.12$ \\
\hline 35 & 2071 & Humulene epoxide II & $\mathrm{C}_{15} \mathrm{H}_{24} \mathrm{O}$ & $0.11 \pm 0.01$ \\
\hline 36 & 2077 & 1-Tridecanol & $\mathrm{C}_{13} \mathrm{H}_{28} \mathrm{O}$ & $1.24 \pm 0.11$ \\
\hline 37 & 2113 & Cumin alcohol & $\mathrm{C}_{10} \mathrm{H}_{14} \mathrm{O}$ & $0.11 \pm 0.02$ \\
\hline 38 & 2269 & Guaia-6,10(14)-dien- $4 \beta$-ol & $\mathrm{C}_{15} \mathrm{H}_{24} \mathrm{O}$ & $0.09 \pm 0.01$ \\
\hline \multicolumn{2}{|c|}{ Total } & \multicolumn{3}{|c|}{$96.99 \pm 1.62$} \\
\hline
\end{tabular}

${ }^{a}$ Relative retention indices (RRI). ${ }^{\mathrm{b}}$ Order of elution in Innowax column.

\subsection{The Effect of ADEO on Oxidative State of Sunflower Oil}

AV is applied to measure the amount of free fatty acids in edible oils $[6,7,24]$. Furthermore, during the oxidation of edible oils, the primary products hydroperoxides are manufactured, which can decompose into all kinds of secondary products including carbonyls and aldehydes, and the primary products and secondary products are severally measured by PV and AnV. Reflecting the initial/later sections of the oxidation process, the TOTOX value was applied to determine the primary/secondary oxidation products [25-27].

Therefore, AV, PV, AnV, and TOTOX can be employed as indicators of oxidation of edible oils [28]. In the high-temperature storage for 24 days in $65^{\circ} \mathrm{C}$, as time went on, $\mathrm{AV}, \mathrm{PV}, \mathrm{AnV}$, and TOTOX were gradually increased in sample IV (Figure 1). Compared with this sample, after the addition of ADEO at $800 \mathrm{ppm}$, the elevated AV, PV, AnV, and TOTOX and were markedly reduced to $0.57 \mathrm{mg} \mathrm{KOH} / \mathrm{kg}$, $71.2 \mathrm{meq} \mathrm{O}_{2} / \mathrm{kg}$, 8.1, and 165.8 at the end of the storage $(p<0.01$ or $p<0.05)$, respectively. In addition, 
together with TBHQ at $100 \mathrm{ppm}, \mathrm{ADEO}$ at $400 \mathrm{ppm}$ also was able to significantly reduce the elevated AV, PV, AnV, and TOTOX to $0.53 \mathrm{mg} \mathrm{KOH} / \mathrm{kg}, 66.1 \mathrm{meq} \mathrm{O}_{2} / \mathrm{kg}$, 7.6, and 158.5 on the 24th day $(p<0.01$ or $p<0.05)$, respectively. Meanwhile, TBHQ could prominently restrict the improvement of AV, PV, AnV, and TOTOX as well $(p<0.01$ or $p<0.05)$. The results revealed that ADEO at $800 \mathrm{ppm}$ and ADEO at $400 \mathrm{ppm} / \mathrm{TBHQ}$ at $100 \mathrm{ppm}$ could improve the oxidative state of sunflower oil, indicating that two schemes could ameliorate the oxidative state of sunflower oil like TBHQ. Quite interestingly, the synergistic effect of ADEO and TBHQ in inhibiting the oxidation of sunflower oil was perfectly demonstrated. Recently, the essential oil from Teucrium polium was demonstrated to suppress the changes for AV and PV during the storage of canola oil, and the essential oil of Thymbra spicata was found to suppress the alteration of PV and $\mathrm{AnV}$ in the deep-fat frying procedure of palm olein $[29,30]$. The results were in conformity with these reports.
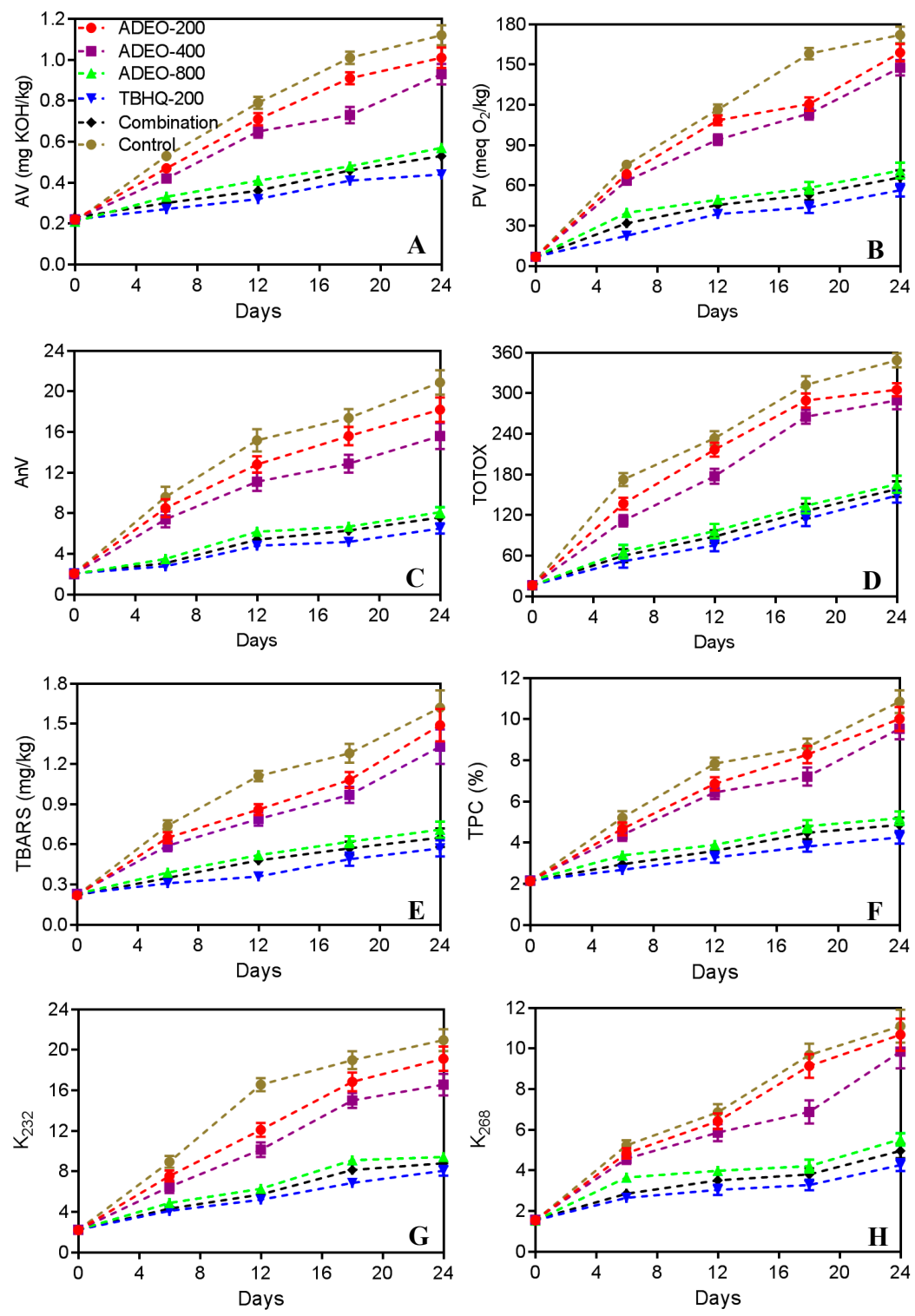

Figure 1. Acid value $(\mathrm{AV})(\mathrm{A})$, peroxide value $(\mathrm{PV})(\mathbf{B}), p$-anisidine value $(\mathrm{AnV})(\mathbf{C})$, total oxidation value (TOTOX) (D), thiobarbituric acid reactive substances (TBARS) (E), total polar compounds (TPC) (F), $\mathrm{K}_{232}(\mathbf{G})$, and $\mathrm{K}_{268}(\mathbf{H})$ of sunflower oil samples in the high-temperature storage influenced by ADEO. 
During the degradation of edible oils, hydroperoxides, the primary products, always react with $\mathrm{O}_{2}$ to manufacture MDA that always results in the off-flavor of oxidized oils [5]. Meanwhile, the high temperature can lead to the production of polar compounds, which are regarded nonvolatile compounds with higher polarity [31]. The amount of MDA and polar compounds is determined as TBARS and TPC, respectively. In addition, conjugated dienes and conjugated trienes could be generated in the oxidation of edible oils, which in turn induce absorption peaks at $232 \mathrm{~nm}$ and $268 \mathrm{~nm}$ so that $K_{232}$ and $K_{268} \mathrm{~nm}$ could be applied to assess the levels of conjugated dienes and conjugated trienes $[6,7,32]$. During the high-temperature storage process, the values for TBARS, TPC, $\mathrm{K}_{232}$, and $\mathrm{K}_{268}$ sharply rose in sample VI (Figure 1). The addition of ADEO at $800 \mathrm{ppm}$ could obviously inhibit the increase of TBARS, TPC, $\mathrm{K}_{232}$, and $\mathrm{K}_{268}$ to $0.71 \mu \mathrm{g} / \mathrm{mL}, 5.19 \%, 9.43$, and $5.54(p<0.01$ or $p<0.05)$, respectively, on the 24th days, in relation to sample VI. Additionally, ADEO at $400 \mathrm{ppm}$ and TBHQ at $100 \mathrm{ppm}$ could obviously control the increase of TBARS, TPC, $\mathrm{K}_{232}$, and $\mathrm{K}_{268}$ to $0.65 \mu \mathrm{g} / \mathrm{mL}, 4.86 \%$, 8.81 , and 4.97 on the 24 th days ( $p<0.01$ or $p<0.05$ ), respectively. For TBHQ, the positive control, it observably decreased the values of TBARS, TPC, $K_{232}$, and $K_{268}$ on the 24th days $(p<0.01$ or $p<0.05)$, too. Also, the synergistic effect of ADEO and TBHQ in restricting the degradation of sunflower oil was found. Recently, the essential oil of T. polium was demonstrated to control the elevation of TPC of canola oil during the storage [30]. Z. multifiora and Rosmarinus officinalis essential oils were demonstrated to hinder TBARS, $K_{232}$, and $K_{268}$ of olive oil during the storage [32]. The results were in line with these reports.

In high-temperature storage, the unsaturated fatty acids are always transformed to saturated fatty acid during the oxidation reaction [32]. Therefore, the fatty acid compositions of edible oils could be used as a reflection of the degree of oxidation. In the determination of fatty acid composition (Table 2), $\mathrm{ADEO}$ at $800 \mathrm{ppm}$ and $\mathrm{ADEO}$ at $400 \mathrm{ppm} / \mathrm{TBHQ}$ at $100 \mathrm{ppm}$ were able to exert similar efficacy to TBHQ in stopping the changing of fatty acid composition during the storage, i.e., both of them were able to memorably suppressed the decrease of oleic acid (C18:1) and linoleic acid (C18:2) in comparison with sample VI at the end of storage, so that ADEO at $800 \mathrm{ppm}$ and ADEO at $400 \mathrm{ppm} / \mathrm{TBHQ}$ at $100 \mathrm{ppm}$ could ameliorate the quality of sunflower oil in the storage period. 
Table 2. Fatty acid composition of sunflower oil samples at $65^{\circ} \mathrm{C}$ for 24 days influenced by ADEO a

\begin{tabular}{|c|c|c|c|c|c|c|c|c|c|}
\hline Samples & Days & $\mathrm{C} 14: 0^{\mathrm{c}}$ & C16:0 & C16:1 & C18:0 & C18:1 & C18:2 & C18:3 & C24:0 \\
\hline \multirow{3}{*}{ Sample I } & 0 & $0.34 \pm 0.01$ & $14.14 \pm 0.11$ & $1.92 \pm 0.02$ & $5.57 \pm 0.05$ & $14.34 \pm 0.11$ & $61.25 \pm 0.54$ & $0.75 \pm 0.01$ & $0.32 \pm 0.01$ \\
\hline & 12 & $0.36 \pm 0.01$ & $16.12 \pm 0.14^{\mathrm{c}}$ & $1.85 \pm 0.01$ & $6.23 \pm 0.04^{c}$ & $13.96 \pm 0.13$ & $59.18 \pm 0.41$ & $0.64 \pm 0.01^{c}$ & $0.34 \pm 0.01$ \\
\hline & 24 & $0.39 \pm 0.01^{c}$ & $19.11 \pm 0.13^{d}$ & $1.75 \pm 0.01^{\mathrm{c}}$ & $7.43 \pm 0.05^{\mathrm{d}}$ & $13.30 \pm 0.16^{\mathrm{c}}$ & $55.75 \pm 0.45^{\mathrm{c}}$ & $0.59 \pm 0.01^{\mathrm{d}}$ & $0.37 \pm 0.01^{c}$ \\
\hline \multirow{3}{*}{ Sample II } & 0 & $0.34 \pm 0.01$ & $14.14 \pm 0.11$ & $1.92 \pm 0.02$ & $5.57 \pm 0.05$ & $14.34 \pm 0.11$ & $61.25 \pm 0.54$ & $0.75 \pm 0.01$ & $0.32 \pm 0.01$ \\
\hline & 12 & $0.36 \pm 0.01$ & $16.09 \pm 0.13^{c}$ & $1.87 \pm 0.02$ & $6.20 \pm 0.06^{c}$ & $13.98 \pm 0.13$ & $59.22 \pm 0.46$ & $0.65 \pm 0.01^{\mathrm{c}}$ & $0.33 \pm 0.01$ \\
\hline & 24 & $0.39 \pm 0.01^{c}$ & $19.08 \pm 0.12^{d}$ & $1.78 \pm 0.01^{\mathrm{c}}$ & $7.39 \pm 0.05^{\mathrm{d}}$ & $13.32 \pm 0.15^{\mathrm{c}}$ & $55.76 \pm 0.41^{c}$ & $0.60 \pm 0.01^{\mathrm{d}}$ & $0.37 \pm 0.01^{\mathrm{c}}$ \\
\hline \multirow{3}{*}{ Sample III } & 0 & $0.34 \pm 0.01$ & $14.14 \pm 0.11$ & $1.92 \pm 0.02$ & $5.57 \pm 0.05$ & $14.34 \pm 0.11$ & $61.25 \pm 0.54$ & $0.75 \pm 0.01$ & $0.32 \pm 0.01$ \\
\hline & 12 & $0.35 \pm 0.01$ & $14.37 \pm 0.12^{\mathrm{e}}$ & $1.87 \pm 0.01$ & $5.71 \pm 0.05^{\mathrm{e}}$ & $14.22 \pm 0.12$ & $61.02 \pm 0.45$ & $0.69 \pm 0.01^{\mathrm{e}}$ & $0.33 \pm 0.01$ \\
\hline & 24 & $0.39 \pm 0.01^{\mathrm{c}}$ & $14.48 \pm 0.14^{\mathrm{e}}$ & $1.79 \pm 0.01$ & $5.93 \pm 0.04^{\mathrm{f}}$ & $14.10 \pm 0.14^{\mathrm{e}}$ & $60.92 \pm 0.41^{\mathrm{e}}$ & $0.62 \pm 0.01^{\mathrm{e}}$ & $0.36 \pm 0.01$ \\
\hline \multirow{3}{*}{ Sample IV } & 0 & $0.34 \pm 0.01$ & $14.14 \pm 0.11$ & $1.92 \pm 0.02$ & $5.57 \pm 0.05$ & $14.34 \pm 0.11$ & $61.25 \pm 0.54$ & $0.75 \pm 0.01$ & $0.32 \pm 0.01$ \\
\hline & 12 & $0.37 \pm 0.01$ & $14.39 \pm 0.12^{\mathrm{e}}$ & $1.85 \pm 0.01$ & $5.74 \pm 0.05^{\mathrm{e}}$ & $14.20 \pm 0.12$ & $61.06 \pm 0.45$ & $0.65 \pm 0.01^{\mathrm{e}}$ & $0.31 \pm 0.01$ \\
\hline & 24 & $0.40 \pm 0.01^{\mathrm{c}}$ & $14.46 \pm 0.14^{\mathrm{e}}$ & $1.81 \pm 0.01$ & $5.96 \pm 0.04^{\mathrm{f}}$ & $14.07 \pm 0.14^{\mathrm{e}}$ & $60.90 \pm 0.41^{\mathrm{e}}$ & $0.64 \pm 0.01^{\mathrm{e}}$ & $0.35 \pm 0.01$ \\
\hline \multirow{3}{*}{ Sample V } & 0 & $0.34 \pm 0.01$ & $14.14 \pm 0.11$ & $1.92 \pm 0.02$ & $5.57 \pm 0.05$ & $14.34 \pm 0.11$ & $61.25 \pm 0.54$ & $0.75 \pm 0.01$ & $0.32 \pm 0.01$ \\
\hline & 12 & $0.35 \pm 0.01$ & $14.38 \pm 0.12^{\mathrm{e}}$ & $1.88 \pm 0.01$ & $5.73 \pm 0.05^{\mathrm{e}}$ & $14.18 \pm 0.12$ & $61.06 \pm 0.45$ & $0.65 \pm 0.01^{\mathrm{e}}$ & $0.33 \pm 0.01$ \\
\hline & 24 & $0.39 \pm 0.01^{c}$ & $14.49 \pm 0.14^{\mathrm{e}}$ & $1.80 \pm 0.01$ & $5.95 \pm 0.04^{\mathrm{f}}$ & $14.06 \pm 0.14^{\mathrm{e}}$ & $60.96 \pm 0.41^{\mathrm{e}}$ & $0.59 \pm 0.01^{\mathrm{e}}$ & $0.36 \pm 0.01$ \\
\hline \multirow{3}{*}{ Sample VI } & 0 & $0.34 \pm 0.01$ & $14.14 \pm 0.11$ & $1.92 \pm 0.02$ & $5.57 \pm 0.05$ & $14.34 \pm 0.11$ & $61.25 \pm 0.54$ & $0.75 \pm 0.01$ & $0.32 \pm 0.01$ \\
\hline & 12 & $0.36 \pm 0.01$ & $16.12 \pm 0.14^{\mathrm{c}}$ & $1.88 \pm 0.01$ & $6.20 \pm 0.04^{c}$ & $13.93 \pm 0.13$ & $59.21 \pm 0.41$ & $0.63 \pm 0.01^{\mathrm{c}}$ & $0.32 \pm 0.01$ \\
\hline & 24 & $0.39 \pm 0.01^{c}$ & $19.13 \pm 0.13^{d}$ & $1.78 \pm 0.01^{c}$ & $7.40 \pm 0.05^{\mathrm{d}}$ & $13.28 \pm 0.16^{c}$ & $55.78 \pm 0.45^{c}$ & $0.59 \pm 0.01^{\mathrm{d}}$ & $0.34 \pm 0.01^{c}$ \\
\hline
\end{tabular}

${ }^{\text {a }}$ Values are expressed as means $\pm \mathrm{SD}(\mathrm{n}=6) .{ }^{\mathrm{b}} \mathrm{C} 14: 0$, myristic acid; C16:0, palmitic acid; C16:1, palmitoleic acid; C18:0, stearic acid; C18:1, oleic acid; C18:2, linoleic acid; C18:3, linolenic acid; C24:0, tetracosanoic acid. ${ }^{\mathrm{c}}$ As compared to the same group on day $0: p<0.05 .{ }^{\mathrm{d}}$ As compared to the same group on day $0: p<0.01 .{ }^{\mathrm{e}}$ As compared to group I on the same day: $p<0.05 .{ }^{\mathrm{f}}$ As compared to group I on the same day: $p<0.01$ 


\subsection{The Effect of ADEO on Sensory Evaluation of Sunflower Oil}

As described in Figure 2, after high-temperature storage at $65^{\circ} \mathrm{C}$ for 24 days, ADEO at 200, 400, and $800 \mathrm{ppm}$ were capable of increasing the flavor $(3.81,4.12$, and 4.66 , respectively), aroma $(4.15,4.24$, and 4.55 , respectively), and overall acceptability $(3.47,3.61$, and 4.09 , respectively) of sunflower oil $(p<0.05)$. In fact, A. dahurica cv. Yubaizhi has long been involved in the preparation of Chinese foods; the sensory evaluation here suggests that the spice can be applied in the development of flavored sunflower oil. In recent years, the essential oils from spices have exhibited significant antioxidative effects in sunflower oil in the high-temperature storage process and have enhanced its customers' acceptance. For example, Coriandrum sativum essential oil at $1200 \mathrm{ppm}$ and Punica granatum essential oil at $800 \mathrm{ppm}$ not only improved the oxidative state of sunflower oil in the accelerated storage but also increased its sensory attributes $[16,33]$. Therefore, in particular, the flavored sunflower oil prepared using spice essential oils is worthy of investigation in the future.

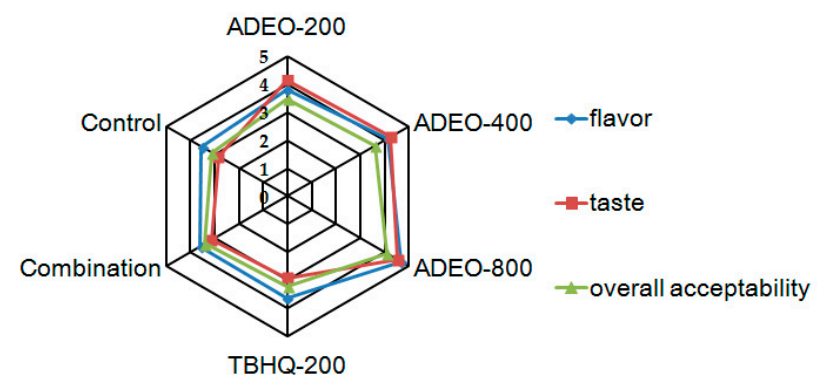

Figure 2. Sensory evaluation of sunflower oils samples influenced by ADEO: Values are expressed as means \pm SD $(n=100)$ of flavor, taste, and overall acceptability.

\subsection{The Effect of Active Compounds from ADEO on Sunflower Oil}

As showed, in high-temperature storage for 24 days at $65^{\circ} \mathrm{C}$, as time went on, the value of $\mathrm{AV}, \mathrm{PV}$, AnV, TOTOX, TBARS, TPC, $K_{232}$, and $K_{268}$ of the sunflower oil were gradually increased in sample IV (Figure 3). Compared with this sample, after the addition of myrcene at $69.8 \mathrm{ppm}$, the elevated AV, PV, $\mathrm{AnV}$, and TOTOX were markedly reduced to $0.59 \mathrm{mg} \mathrm{KOH} / \mathrm{kg}$, $70.8 \mathrm{meq} \mathrm{O}_{2} / \mathrm{kg}$, 8.3, and 166.2 on the 24th day $(p<0.01$ or $p<0.05)$, respectively. In the meantime, the addition of myrcene at $69.8 \mathrm{ppm}$ could obviously inhibit the increase of TBARS, TPC, $\mathrm{K}_{232}$, and $\mathrm{K}_{268}$ to $0.72 \mu \mathrm{g} / \mathrm{mL}, 5.21 \%, 9.56$, and 5.58 on the 24th day $(p<0.01$ or $p<0.05)$, respectively, compared with the sample VI. Furthermore, the additions of myrcene at $69.8 \mathrm{ppm}$, terpinen-4-ol at $64.1 \mathrm{ppm}$, and cryptone at $53.4 \mathrm{ppm}$ could improve the flavor $(4.69,4.15$, and 3.82 , respectively), aroma $(4.58,4.29$, and 4.17 , respectively), and overall acceptability $(4.25,3.66$, and 3.51, respectively) of sunflower oil $(p<0.05)$ (Figure 4$)$. The results of myrcene at $69.8 \mathrm{ppm}$ in the studies of oxidative stability and sensory properties were quite close to that of ADEO at $800 \mathrm{ppm}$. Therefore, the antioxidative activity of ADEO in sunflower oil in high-temperature storage should be attributed to that of one of its main compounds, myrcene. In fact, the antioxidant effect of myrcene has never been reported until now, except that it was demonstrated to mitigate ammonia-induced superoxide dismutase (SOD) activity and MDA level increase and glutathione peroxidase (GPx) and catalase (CAT) activity decrease in common carp blood [34]. 

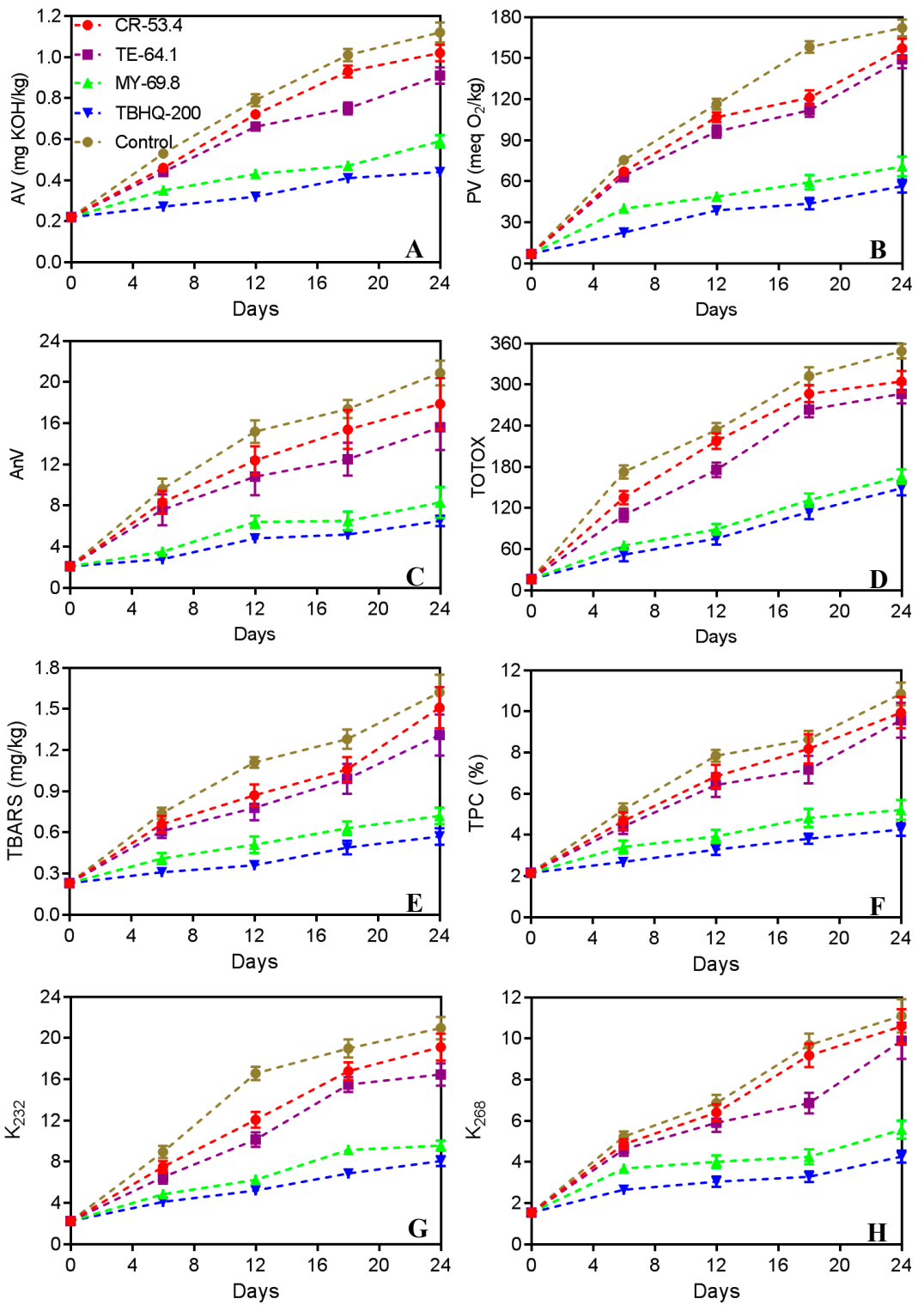

Figure 3. AV (A), PV (B), AnV (C), TOTOX (D), TBARS (E), TPC (F), $K_{232}(\mathbf{G})$, and $\mathrm{K}_{268}(\mathbf{H})$ of sunflower oil samples during high-temperature storage influenced of myrcene, terpinen-4-ol, and cryptone.

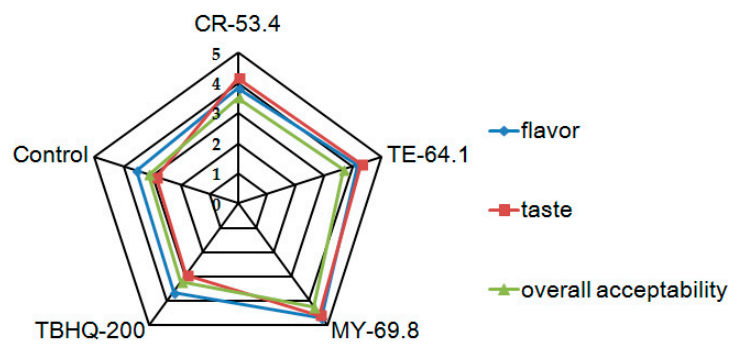

Figure 4. Sensory evaluation of sunflower oils samples influenced by myrcene, terpinen-4-ol, and cryptone: Values are expressed as means \pm SD $(n=100)$ of flavor, taste, and overall acceptability.

\section{Conclusions}

During the investigation, $\mathrm{ADEO}$ at $800 \mathrm{ppm}$ was found to improve the oxidative state of sunflower oil and to ameliorate the flavor, aroma, and overall acceptability of sunflower oil in high-temperature storage for 24 days at $65^{\circ} \mathrm{C}$. Meanwhile, ADEO at $400 \mathrm{ppm} / \mathrm{TBHQ}$ at $100 \mathrm{ppm}$ could also elevate the oxidative stability of sunflower oil. Interestingly, the antioxidative effect of the essential oil 
was attributed to one of its active compounds, myrcene. The preparation of flavored sunflower oil using ADEO is quite a useful method to increase its oxidative stability. Additionally, the functional mechanisms of antioxidant effects of the combination of ADEO and TBHQ and myrcene in sunflower oil will be illuminated in our experimental plan.

Author Contributions: Conceptualization, D.W. and C.W.; methodology, Y.M.; software, Y.M.; validation, D.W., C.W., and X.W.; formal analysis, Y.M.; investigation, Y.M.; resources, D.W.; data curation, C.W.; writing-original draft preparation, C.W.; writing-review and editing, C.W. and F.B.; supervision, D.W.; project administration, D.W.; funding acquisition, D.W. All authors have read and agreed to the published version of the manuscript.

Funding: This research was supported by the Doctor Research Fund of Henan University of Technology (2017BS032); by the Fundamental Research Fund for the Henan Provincial Colleges and Universities (2018QNJH20); by the Key Research Fund in Science and Technology of Henan Province, China (192102110210); and by the Research Fund from China Agriculture Research System (CARS14-1-29).

Acknowledgments: The authors thank Wenchang Fan in Institute of Chinese Medicine Health Care, Guangdong Food and Drug Vocational College, Guangzhou for his help in plant identification and sensory evaluation.

Conflicts of Interest: The authors declare no conflict of interest.

\section{References}

1. Tavakoli, J.; Estakhr, P.; Jelyani, A.Z. Effect of unsaponifiable matter extracted from Pistacia khinjuk fruit oil on the oxidative stability of olive oil. J. Food Sci. Techol. 2017, 54, 2980-2988. [CrossRef] [PubMed]

2. Zamindar, N.; Bashash, M.; Khorshidi, F.; Serjouie, A.; Shirvani, M.A.; Abbasi, H.; Sedaghatdoost, A. Antioxidant efficacy of soybean cake extracts in soy oil protection. J. Food Sci. Techol. 2017, 54, 2077-2084. [CrossRef] [PubMed]

3. Upadhyay, R.; Mishra, H.N. Classification of sunflower oil blends stabilized by oleoresin rosemary (Rosmarinus officinalis L.) using multivariate kinetic approach. J. Food Sci. 2015, 80, E1746-E1754. [CrossRef] [PubMed]

4. Asensio, C.M.; Nepote, V.; Grosso, N.R. Sensory attribute preservation in extra virgin olive oil with addition of oregano essential oil as natural antioxidant. J. Food Sci. 2012, 77, S294-S301. [CrossRef] [PubMed]

5. Chen, X.Q.; Zhang, Y.; Zu, Y.G.; Yang, L.; Lu, Q.; Wang, W. Antioxidant effects of rosemary extracts on sunflower oil compared with synthetic antioxidants. Int. J. Food Sci. Techol. 2014, 49, 385-391. [CrossRef]

6. Blasia, F.; Rocchetti, G.; Montesano, D.; Lucini, L.; Chiodelli, G.; Ghisoni, S.; Baccolo, G.; Simonetti, M.S.; Cossignani, L. Changes in extra-virgin olive oil added with Lycium barbarum L. carotenoids during frying: Chemical analyses and metabolomic approach. Food Res. Int. 2018, 105, 507-516. [CrossRef]

7. Montesano, D.; Rocchetti, G.; Cossignani, L.; Senizza, B.; Pollini, L.; Lucini, L.; Blasi, F. Untargeted metabolomics to evaluate the stability of extra-virgin olive oil with added Lycium barbarum carotenoids during storage. Foods 2019, 8, 179. [CrossRef]

8. Shan, B.; Cai, Y.Z.; Sun, M.; Corke, H. Antioxidant capacity of 26 spice extracts and characterization of their phenolic constituents. J. Agric. Food Chem. 2005, 53, 7749-7759. [CrossRef]

9. Liang, Y.; Ding, Y.; Zhang, L.J.; Liu, X.J. Antioxidant activities of nine selected culinary spices from China. J. Northeast Agric. Univ. 2015, 22, 50-57.

10. Dang, M.N.; Takácsová, M.; Nguyen, D.V.; Kristiánová, K. Antioxidant activity of essential oils from various spices. Mol. Nutr. Food Res. 2001, 45, 64-66. [CrossRef]

11. Hashemi, M.B.; Niakousari, M.; Saharkhiz, M.J.; Eskandari, M.H. Stabilization of sunflower oil with Carum copticum Benth \& Hook essential oil. J. Food Sci. Techol. 2014, 51, 142-147.

12. Chen, L.; Yang, H.; Yu, C.; Yuan, M.; Li, H. High hepatic exposure of furanocoumarins in Radix Angelica dahuricae is associated with transporter mediated active uptake. J. Ethnopharmacol. 2018, 212, 74-85. [CrossRef] [PubMed]

13. Wang, C.; Sun, J.; Li, H.; Yang, X.; Liu, H.; Chen, J. In vivo anti-inflammatory activities of the essential oil from Radix Angelicae dahuricae. J. Nat. Med. 2016, 70, 563-570. [CrossRef] [PubMed]

14. Zheng, L.H.; Wang, P.J.; Li, W.; Feng, D. Chemical composition of essential oil from Angelica dahurica roots and its DPPH radical scavenging effect. Food Sci. 2014, 35, 180-183.

15. Upadhyay, R.; Mishra, H.N. Predictive modeling for shelf life estimation of sunflower oil blended with oleoresin rosemary (Rosmarinus officinalis L.) and ascorbyl palmitate at low and high temperatures. LWT Food Sci. Technol. 2015, 60, 42-49. [CrossRef] 
16. Wang, D.; Fan, W.; Guan, Y.; Huang, H.; Yi, T.; Ji, J. Oxidative stability of sunflower oil flavored by essential oil from Coriandrum sativum L. during accelerated storage. LWT Food Sci. Technol. 2018, 98, 268-275. [CrossRef]

17. Tabanca, N.; Gao, Z.; Demirci, B.; Techen, N.; Wedge, D.E.; Ali, A.; Sampson, B.J.; Werle, C.; Bernier, U.R.; Khan, I.A.; et al. Molecular and phytochemical investigation of Angelica dahurica and Angelica pubescentis essential oils and their biological activity against Aedes aegypti, Stephanitis pyrioides, and Colletotrichum species. J. Agric. Food Chem. 2014, 62, 8848-8857. [CrossRef]

18. Zhao, A.; Yang, X.; Yang, X.; Wang, W.; Tao, H. GC-MS analysis of essential oil from root of Angelica dahurica cv. Qibaizhi. China J. Chin. Mater. Med. 2011, 36, 603-607.

19. Wang, X.; Wang, X.; Wang, W.; Yang, Y.; Wang, L.; Wu, Y. Quality and trans fatty acids contents of sunflower oils from parts of Shihezi in Xinjiang. Sci. Technol. Cereal Oil Food 2016, 24, 30-35.

20. Chandran, J.; Nayana, N.; Ronishi, N.; Nisha, P. Oxidative stability, thermal stability and acceptability of coconut oil flavored with essential oils from black pepper and ginger. J. Food Sci. Techol. 2017, 54, 144-152. [CrossRef]

21. Adiani, V.; Gupta, S.; Chatterjee, S.; Variyar, P.S.; Sharma, A. Activity guided characterization of antioxidant components from essential oil of Nutmeg (Myristica fragrans). J. Food Sci. Techol. 2015, 52, 221-230. [CrossRef]

22. Gao, Y.; Wang, Z.; Yang, C.; Wu, G.; Chen, Y.; Kuang, H. Analysis of the volatile components of Angelica dahurica by GC-MS. Chem. Eng. 2016, 30, 20-22. [CrossRef]

23. Zhao, A.; Yang, X.; Yang, X.; Tao, H.; Yu, J.; Wang, W. GC-MS analysis of the chemical components of volatile oil from the root of Angelica dahurica. Chin. J. Pharm. Anal. 2012, 32, 763-768.

24. Sayyari, Z.; Farahmandfar, R. Stabilization of sunflower oil with pussy willow (Salix aegyptiaca) extract and essential oil. Food Sci. Nutr. 2017, 5, 266-272. [CrossRef]

25. Chong, Y.M.; Chang, S.K.; Sia, W.C.M.; Yim, H.S. Antioxidant efficacy of mangosteen (Garcinia mangostana Linn.) peel extracts in sunflower oil during accelerated storage. Food Biosci. 2015, 12, 18-25. [CrossRef]

26. Cossignani, L.; Giua, L.; Simonetti, M.S.; Blasi, F. Volatile compounds as indicators of conjugated and unconjugated linoleic acid thermal oxidation. Eur. J. Lipid Sci. Tech. 2014, 116, 407-412. [CrossRef]

27. Giua, L.; Blasi, F.; Simonetti, M.S.; Cossignani, L. Oxidative modifications of conjugated and unconjugated linoleic acid during heating. Food Chem. 2013, 140, 680-685. [CrossRef]

28. Sadeghi, E.; Karami, F.; Etminan, A. The effect of Ferulago angulata (Schlecht) Boiss essential oil on stabilization of sunflower oil during accelerated storage. J. Food Process. Preserv. 2017, 41, e12745. [CrossRef]

29. Maskan, M.; Horuz, E. Evaluation of antioxidant properties of Za'atar (Thymbra spicata) essential oils as natural antioxidant for stability of palm olein during deep-fat frying process. J. Food Sci. Techol. 2017, 54, 1794-1801. [CrossRef]

30. Sayyad, R.; Farahmandfar, R. Influence of Teucrium polium L. essential oil on the oxidative stability of canola oil during storage. J. Food Sci. Techol. 2017, 54, 3073-3081. [CrossRef]

31. Angelo, P.M.; Jorge, N. Antioxidant evaluation of coriander extract and ascorbyl palmitate in sunflower oil under thermoxidation. J. Am. Oil Chem. Soc. 2008, 85, 1045-1049. [CrossRef]

32. Keramat, M.; Golmakani, M.T.; Aminlari, M.; Shekarforoush, S. Oxidative stability of virgin olive oil supplemented with Zataria multiflora Boiss. and Rosmarinus officinalis L. essential oils during accelerated storage. J. Food Process. Preserv. 2016, 41, e12951. [CrossRef]

33. Wang, D.; Meng, Y.; Zhao, X.; Fan, W.; Yi, T.; Wang, X. Sunflower oil flavored by essential oil from Punica granatum cv. Heyinshiliu peels improved its oxidative stability and sensory properties. LWT Food Sci. Technol. 2019, 111, 55-61. [CrossRef]

34. Hoseini, S.M.; Yousefi, M.; Hoseinifar, S.H.; Doan, H.V. Antioxidant, enzymatic and hematological responses of common carp (Cyprinus carpio) fed with myrcene-or menthol-supplemented diets and exposed to ambient ammonia. Aquaculture 2019, 506, 246-255. [CrossRef]

(C) 2020 by the authors. Licensee MDPI, Basel, Switzerland. This article is an open access article distributed under the terms and conditions of the Creative Commons Attribution (CC BY) license (http://creativecommons.org/licenses/by/4.0/). 